\title{
Augmented Reality Bangunan Bersejarah Berbasis Android (Studi Kasus : Istana Siak Sri Indrapura)
}

\author{
Ause Labellapansa ${ }^{1}$, Mega Restu Asrining Ratri ${ }^{2}$ \\ 1,2Program Studi Teknik Informatika, Fakultas Teknik, Universitas Islam Riau \\ E-mail : ause.labella@eng.uir.ac.id ${ }^{1}$, mega.rar25@gmail.com²
}

\begin{abstract}
Siak Sri Indrapura Palace is one of the historical heritage buildings in Riau commonly known as the Palace of Siak. Public interest in the historic building could have been on the wane due to the lack of information obtained. This of course will result in diminishing returns is also the knowledge of future generations of the past in their own country. One solution that can be done is to use computer assistance through the creation of applications Augmented Reality (AR). AR is a technology that combines the real world with the virtual world. Applications with AR is used to Istana Siak Sri Indrapura based on android so that it can attract people and facilitate the public to obtain information on the Siak Palace. The workings of this application is by pointing the camera to the marker application that has been provided so that it displays 3D objects. Marker used in this study there are three that displays Siak palace, Istana Siak first floor, and second floor of the Palace of Siak.
\end{abstract}

Keywords : Android, Augmented Reality, Siak Palace, Marker, 3D

\begin{abstract}
Abstrak
Istana Siak Sri Indrapura merupakan salah satu bangunan peninggalan bersejarah yang ada di Riau yang biasa dikenal sebagai Istana Siak. Minat masyarakat terhadap bangunan bersejarah bisa saja semakin berkurang dikarenakan kurangnya informasi yang diperoleh. Hal ini tentu saja akan mengakibatkan semakin berkurang pula pengetahuan generasi yang akan datang terhadap sejarah yang ada di negeri sendiri. Salah satu solusi yang dapat dilakukan adalah dengan menggunakan bantuan komputer melalui pembuatan aplikasi Augmented Reality (AR). AR adalah teknologi yang menggabungkan dunia nyata dengan dunia virtual. Aplikasi dengan AR ini digunakan untuk Istana Siak Sri Indrapura berbasis android sehingga dapat menarik minat masyarakat serta mempermudah masyarakat untuk mendapatkan informasi tentang Istana Siak. Cara kerja aplikasi ini adalah dengan mengarahkan kamera aplikasi ke marker yang telah tersedia sehingga menampilkan objek 3D. Marker yang digunakan dalam penelitian ini ada tiga buah yang menampilkan Istana Siak, Istana Siak lantai satu, dan Istana Siak lantai dua.
\end{abstract}

Kata kunci : Android, Augmented Reality, Istana Siak, Marker, 3D

\section{PENDAHULUAN}

Riau merupakan provinsi yang kaya akan sejarah. Di Riau banyak terdapat bangunan-bangunan peninggalan bersejarah, salah satunya adalah Istana Siak Sri Indrapura yang biasa dikenal sebagai Istana Siak. Istana ini merupakan peninggalan bersejarah dari Kerajaan Siak yang dahulunya dihuni oleh Sultan Siak. Istana Siak ini terletak di daerah Siak, Provinsi Riau. Namun sangat disayangkan karena sekarang ini tidak banyak masyarakat yang tertarik untuk mengetahui sejarah dan informasi tentang Istana Siak. Istana Siak lebih diminati sebagai objek wisata untuk foto-foto dan piknik bersama keluarga. Salah satu cara untuk melestarikan bangunan peninggalan sejarah adalah dengan promosi yang memanfaatkan teknologi augmented reality.

Augmented Reality adalah sebuah teknologi yang menggabungkan dunia nyata dengan dunia virtual sehingga kita dapat berinteraksi secara langsung dengan objek 
virtual yang dibuat. Tujuan yang ingin dicapai yaitu membuat aplikasi Augmented Reality bangunan bersejarah Istana Siak Sri Indrapura berbasis android yang dapat mempermudah masyarakat berinteraksi dengan objek 3D Istana Siak Sri Indrapura secara realtime sehingga menarik minat masyarakat terhadap bangunan bersejarah serta mempermudah masyarakat untuk mendapatkan informasi tentang Istana Siak.

\section{METODE PENELITIAN}

\subsection{Pengumpulan Data}

Dalam penelitian ini bahan penelitian didapat dengan cara mencari dan mempelajari dari berbagai sumber yang berkaitan dengan masalah yang diteliti baik dari internet, buku, jurnal ilmiah, dan mengamati langsung keadaan permasalahan yang terjadi di lapangan untuk mendapatkan informasi dengan bertanya langsung kepada pihak yang terkait dalam penelitian, serta mengambil foto untuk kepentingan penelitian ini.

\subsection{Konsep Teori}

\subsubsection{Studi Pustaka}

Sandyarjo Bintarto (2013), membuat aplikasi yang menampilkan Augmented Reality bagian-bagian Candi Borobudur. Dalam penelitian ini, Sandyarjo Bintarto menggunakan aplikasi ARToolkit untuk membuat Augmented Reality. ARToolkit adalah aplikasi untuk membuat Augmented Reality berbasis komputer. Cara kerja ARToolkit adalah dengan menjalankan aplikasi yang secara otomatis akan membuka kamera dan memindai kertas yang sudah mempunyai pola tertentu sehingga dapat menampilkan gambar 3D.

Abas Setiawan, Hanny Haryanto, dan Sari Wijayanti (2012), membuat sebuah aplikasi Augmented Reality yang digunakan untuk mempromosikan Bangunan Lawang Sewu di Kota Semarang. Aplikasi ini dibangun dengan menggunakan FLARToolkit. FLARToolkit adalah aplikasi untuk membuat Augmented Reality berbasis komputer. Cara kerja FLARToolkit adalah dengan menjalankan aplikasi yang secara otomatis akan membuka kamera dan memindai kertas yang sudah mempunyai pola tertentu sehingga dapat menampilkan gambar 3D. Adapun perbedaan dengan aplikasi yang dibangun adalah aplikasi ini masih menggunakan FLARToolkit dimana hanya dapat berjalan di komputer sehingga kurang efisien dalam penggunaannya.

\subsubsection{Augmented Reality}

Augmented Reality adalah sebuah teknologi yang menggabungkan benda maya baik dua dimensi maupun tiga dimensi ke dalam lingkungan nyata lalu memproyeksikan benda-benda maya tersebut dalam waktu nyata [1]. Jadi dapat disimpulkan bahwa Augmented Reality adalah teknologi yang menggabungkan objek virtual dan objek nyata yang bisa disentuh dan dilihat sehingga pengguna dapat berinteraksi secara langsung dengan objek tersebut.

\subsubsection{Istana Siak Sri Indrapura}

Istana Siak Sri Indrapura yang biasa dikenal sebagai Istana Siak merupakan bukti sejarah kerajaan Melayu Islam di Riau. Istana Siak ini dibangun pada masa pemerintahan Sultan Assyaidis Syarif Hasyim Abdul Jalil Syaifuddin pada tahun 1889 yang diberi nama Istana Asserayyah Assyimiyyah. Didalam Istana ini terdapat tanda mata yang diberikan oleh tamu-tamu kerajaan, foto keluarga kerajaan, dan benda-benda kerajaan seperti tombak, kursi, meriam, payung, cermin, keramik, dan lain-lain. Istana Siak juga 
dikenal sebagai Istana Matahari Terbit yang berlokasi di Jalan Sultan Syarif Kasim, Siak, Kabupaten Siak, Riau, Indonesia.

\subsubsection{Android}

Android merupakan sistem operasi berbasis linux yang dirancang untuk perangkat seluler layar sentuh seperti telepon pintar dan komputer tablet [2]. Android bersifat open source dan memungkinkan penggunanya untuk memasang aplikasi baik yang diperoleh dari toko aplikasi seperti Google Play ataupun dengan mengunduh dan memasang berkas apk. Apk adalah paket aplikasi android yang digunakan untuk menyimpan sebuah aplikasi atau program yang akan dijalankan pada perangkat android.

\subsubsection{Marker}

Marker atau penanda adalah ilustrasi hitam dan putih yang berbentuk persegi dengan batas hitam tebal dan latar belakang putih [3]. Komputer akan mengenali posisi dan orientasi marker dan menciptakan dunia virtual 3D yaitu titik $(0,0,0)$ dan 3 sumbu yaitu X,Y,dan Z. Ada beberapa metode yang digunakan pada Augmented Reality, salah satunya adalah yang digunakan dalam penelitian ini yaitu marker based tracking. Marker based tracking adalah pelacakan berbasis marker. Pada penelitian ini digunakan tiga buah marker hitam putih yang telah diregistrasi.

\subsubsection{SketchUp}

SketchUp merupakan sebuah program pemodelan 3D yang dirancang untuk arsitek, desainer, pengembang, pembuat, dan insinyur yang paling banyak penggunanya saat ini [4]. Keunggulan dari SketchUp adalah ringan, ukuran aplikasi kecil, mudah dipelajari, mudah dipergunakan, dukungan pustaka objek yang sangat banyak, dan dukungan aplikasi tambahan yang cukup banyak.

\subsubsection{Unity $3 D$}

Unity 3D adalah sebuah game engine yang memungkinkan pengguna untuk membuat sebuah game 3D dengan mudah dan cepat [5]. Unity dapat mengimpor model dan animasi dari hampir semua aplikasi 3D seperti 3ds Max, Sketchup, Modo, Cinema 4D, Blender dan lain-lain. Unity mendukung pengembangan aplikasi android.

\subsection{Perancangan Sistem}

Sistem yang akan dibangun dapat digambarkan secara detail melalui pengembangan sistem dengan menggunakan alat bantu flowchart yang akan menjelaskan alur sistem dan akan menggambarkan secara visual bagaimana aliran datanya. Adapun didalam aplikasi ini akan dapat menampilkan Istana Siak, Istana Siak lantai satu, dan Istana Siak lantai dua dalam bentuk objek 3D secara realtime, dimana agar dapat menggunakan aplikasi Augmented Reality ini harus memiliki marker agar aplikasi ini dapat berjalan dengan baik. Secara umum alur sistem aplikasi yang dibuat adalah sebagai berikut:

1. User menjalankan aplikasi Augmented Reality Istana Siak yang sudah terpasang di smartphone android.

2. Apabila aplikasi telah siap maka akan muncul halaman utama aplikasi, dimana terdapat button Mulai, Info, dan Keluar.

3. Button Mulai akan menampilkan kamera pada aplikasi yang akan mendeteksi marker yang diarahkan ke kamera aplikasi sehingga menampilkan objek 3D berupa Istana Siak secara realtime. 
4. Button Info akan menampilkan informasi tentang Istana Siak.

5. Button Keluar untuk keluar dari aplikasi Augmented reality Istana Siak.

Keterangan alur sistem aplikasi diatas dapat dilihat pada gambar 2.1.

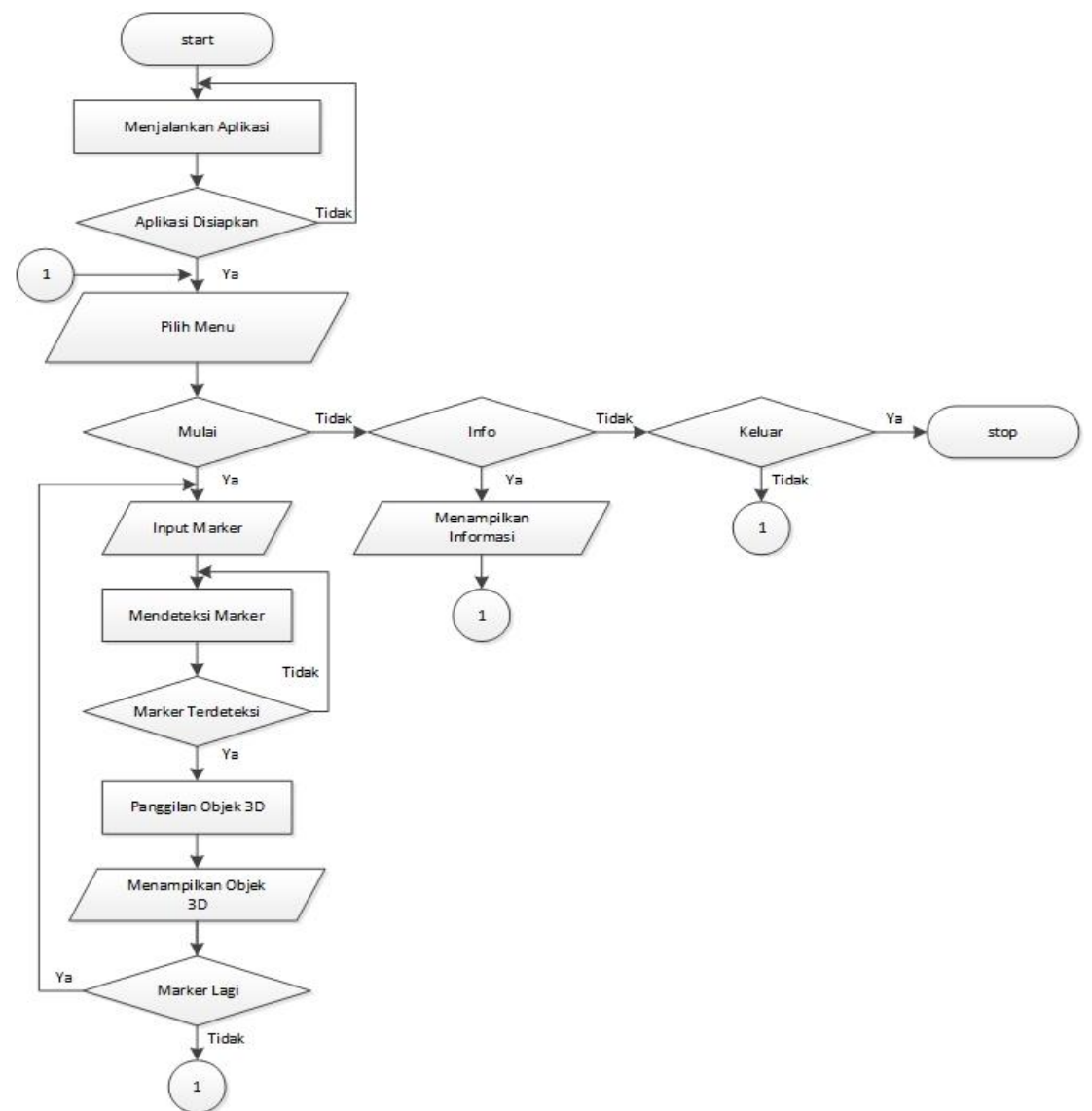

Gambar 2.1 Flowchart Augmented Reality

Berikut adalah gambaran proses alur kerja pendeteksian marker yang dapat dilihat pada gambar 2.2. 


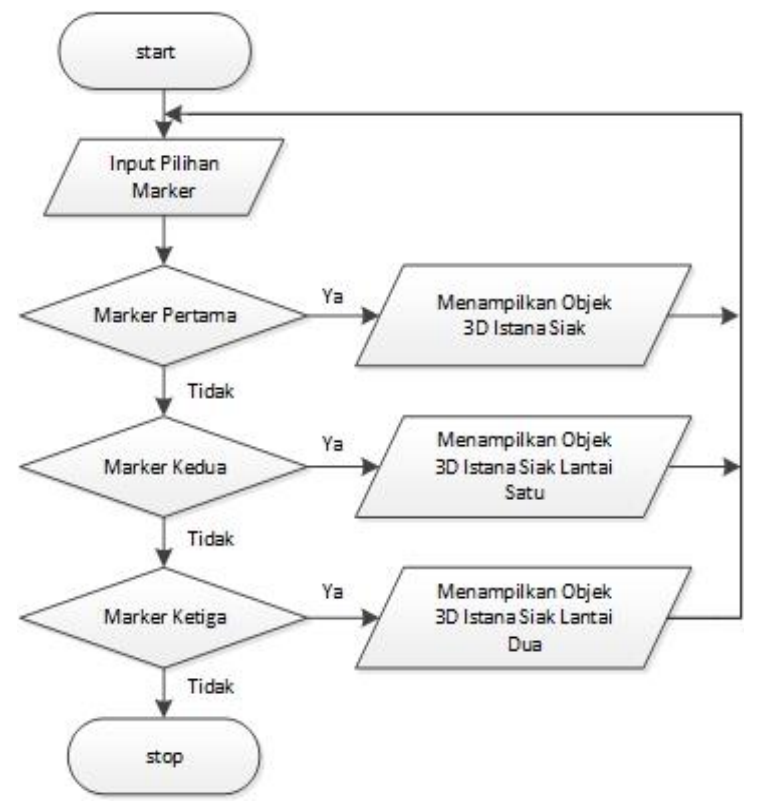

Gambar 2.2 Flowchart Marker

3. HASIL DAN PEMBAHASAN

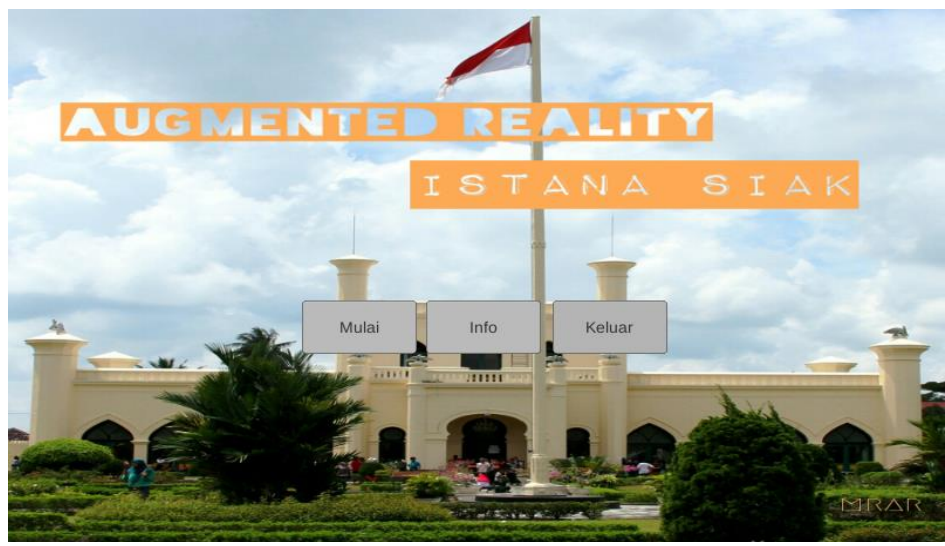

Gambar 3.1 Halaman Utama Aplikasi

Halaman utama aplikasi terdapat tiga pilihan tombol yaitu Mulai, Info, dan Keluar. Tombol Mulai untuk masuk ke kamera aplikasi Augmented Reality yang akan mendeteksi ketiga marker yang telah ditentukan dan menampilkan objek 3D. Hasil dari pendeteksian marker adalah sebagai berikut:

1. Marker Pertama

Marker pertama merupakan marker yang menampilkan keseluruhan Istana Siak Sri Indrapura yang bisa dilihat pada gambar 3.2. 


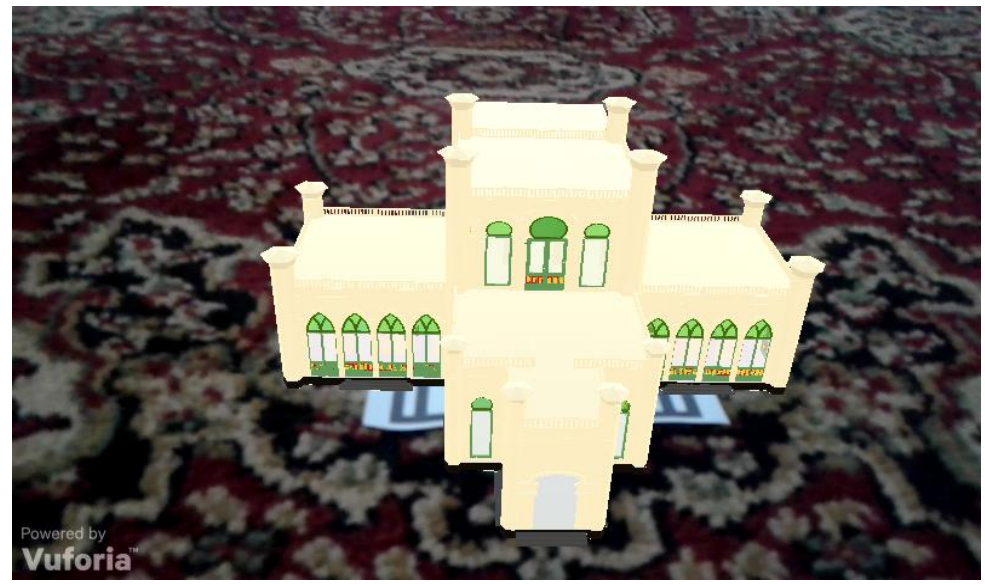

Gambar 3.2 Tampilan Marker Pertama

2. Marker Kedua

Marker kedua ini menampilkan ruang-ruang dan sebagian isi dalam yang ada di lantai satu Istana Siak Sri Indrapura yang bisa dilihat pada gambar 3.3.

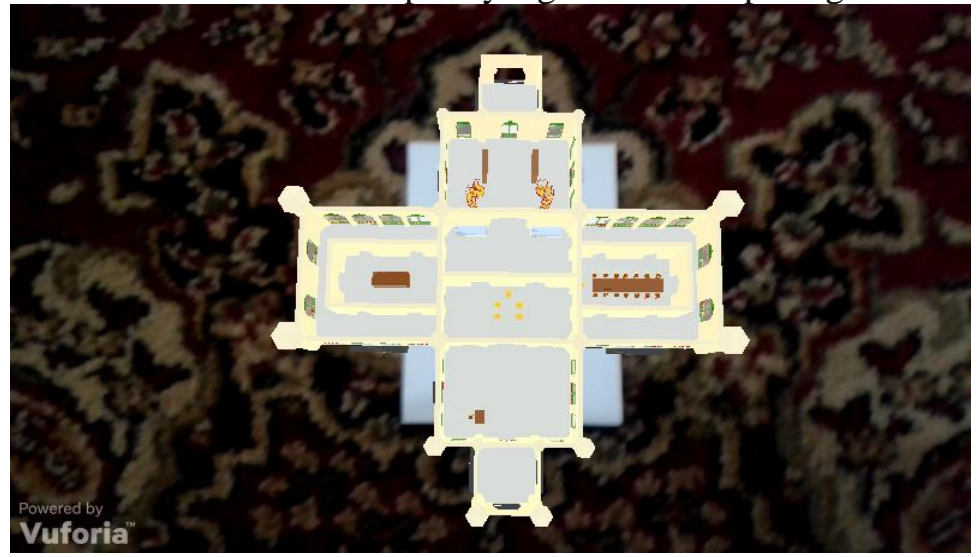

Gambar 3.3 Tampilan Marker Kedua

3. Marker Ketiga

Marker ketiga ini menampilkan ruang-ruang dan sebagian isi dalam yang ada di lantai dua Istana Siak Sri Indrapura yang bisa dilihat pada gambar 3.4.

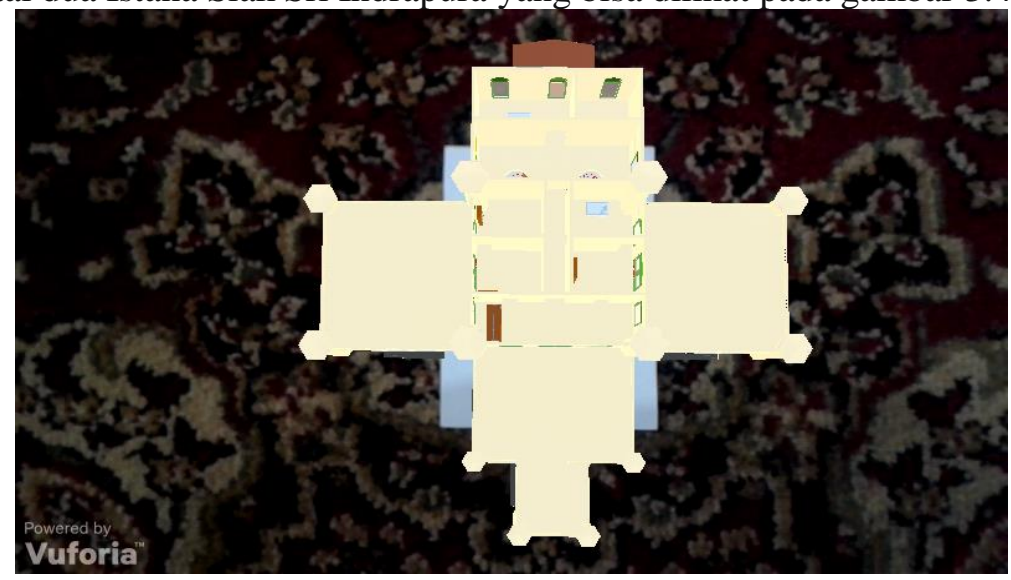

\section{Gambar 3.4 Tampilan Marker Ketiga}

Tombol Info menampilkan informasi tentang Istana Siak berupa sejarah, isi Istana Siak, serta lokasi Istana Siak yang dapat dilihat pada gambar 3.5. 


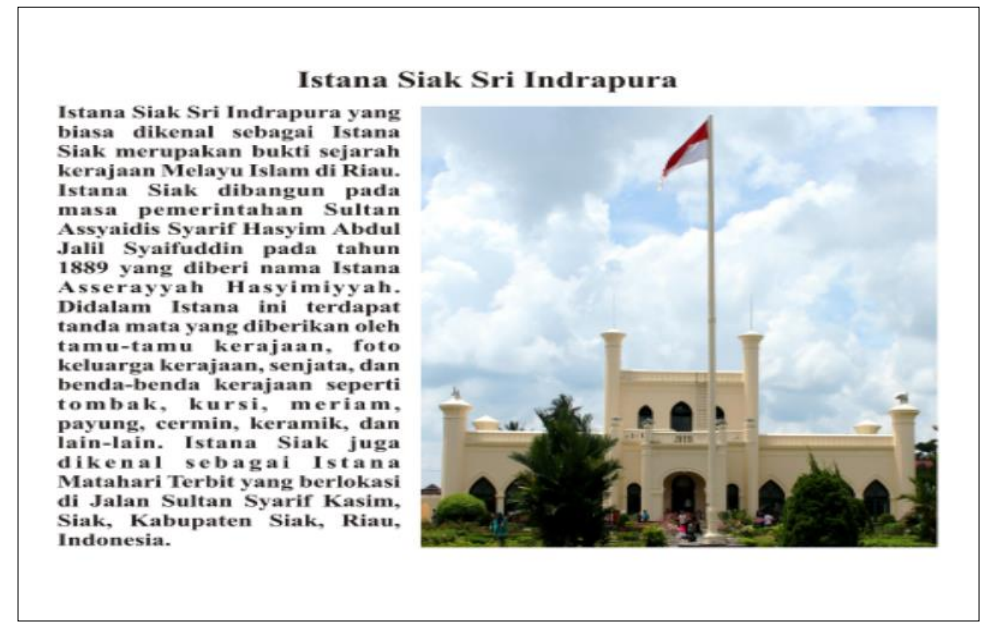

Gambar 3.5 Tampilan Info Aplikasi

\subsection{Pengujian Terhadap Marker}

Pada pengujian ini, dilakukan pengujian pencahayaan, jarak, sudut, marker terhalang objek lain, dan marker lain. Pengujian terhadap marker ini dapat dilihat sebagai berikut:

1. Pencahayaan

Pengujian pencahayaan terhadap marker pertama, kedua, dan ketiga dilakukan sebanyak 5 kali dengan menggunakan smartphone yang sama yang dapat dilihat pada tabel 1 .

Tabel 1. Pengujian Pencahayaan Terhadap Marker

\begin{tabular}{|c|c|}
\hline Kasus yang diuji & Hasil Uji \\
\hline Ruangan dengan cahaya matahari & Muncul objek 3D \\
\hline $\begin{array}{c}\text { Ruangan tertutup dengan cahaya lampu pada siang } \\
\text { hari (tanpa cahaya matahari) }\end{array}$ & Muncul objek 3D \\
\hline $\begin{array}{c}\text { Ruangan tertutup tanpa cahaya lampu pada siang } \\
\text { hari (tanpa cahaya matahari) }\end{array}$ & Tidak muncul objek 3D \\
\hline Ruangan dengan cahaya lampu pada malam hari & Muncul objek 3D \\
\hline Ruangan tanpa cahaya lampu pada malam hari & Tidak muncul objek 3D \\
\hline
\end{tabular}

Berdasarkan pengujian pada tabel 1, dapat diambil kesimpulan bahwa marker tidak bisa terdeteksi apabila marker tidak mendapatkan cahaya sama sekali. Marker hanya bisa terdeteksi dan menampilkan objek 3D apabila marker mendapatkan cahaya, baik itu cahaya matahari ataupun cahaya lampu.

2. Jarak dan Sudut

Pengujian jarak dan sudut terhadap marker pertama, kedua, dan ketiga dilakukan sebanyak 5 kali dengan menggunakan smartphone yang sama dan waktu yang sama yang dapat dilihat pada table 2 .

Tabel 2. Pengujian Jarak dan Sudut Terhadap Marker

\begin{tabular}{|c|c|c|}
\hline Kasus yang diuji & Sudut & Hasil Uji \\
\hline Jarak 10 cm dari marker & $10^{\circ}$ & Muncul objek 3D \\
\cline { 2 - 3 } & $20^{\circ}$ & Muncul objek 3D \\
\cline { 2 - 3 } & $30^{\circ}$ & Muncul objek 3D \\
\hline
\end{tabular}




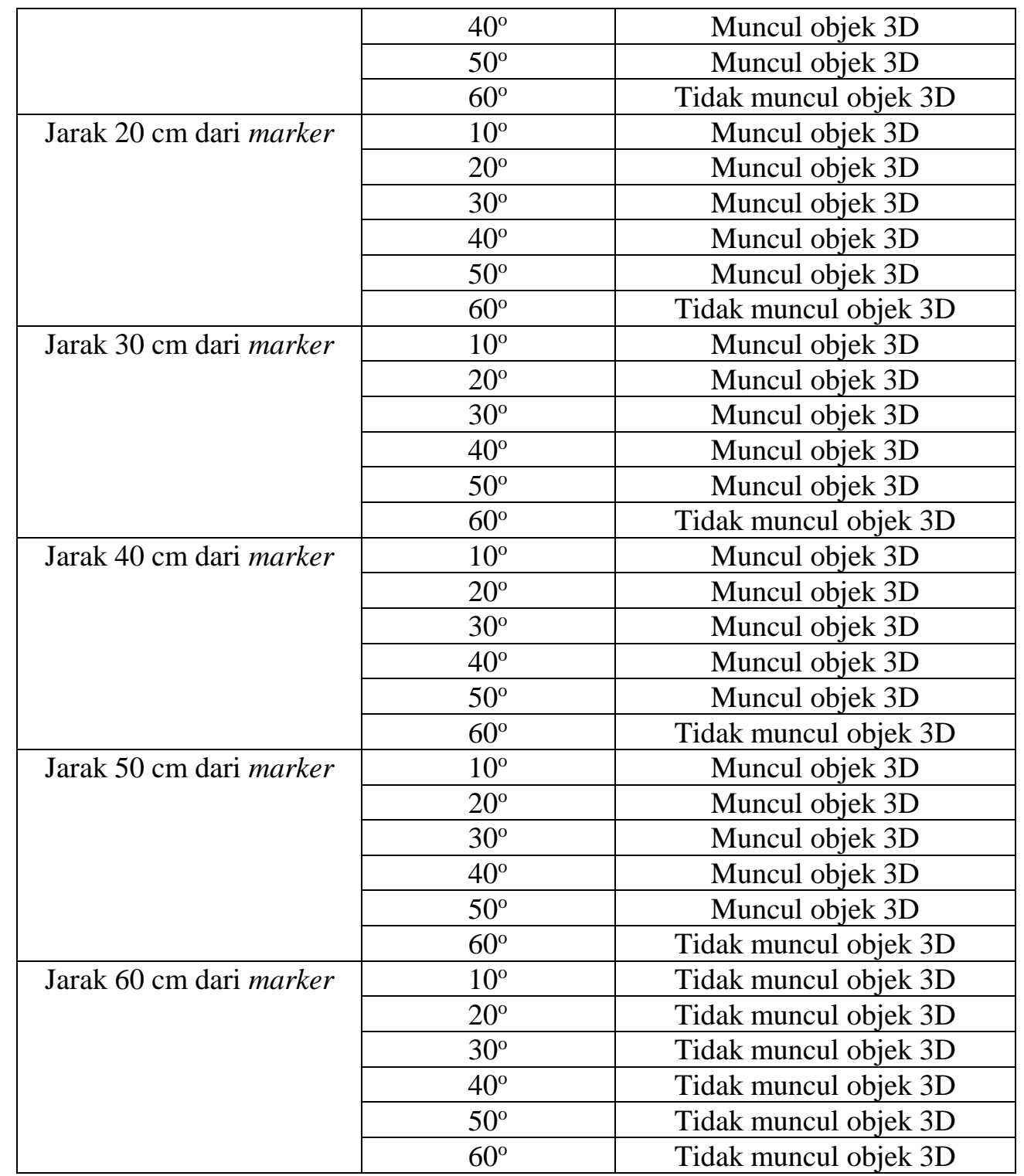

Berdasarkan pengujian pada tabel 2, dapat diambil kesimpulan bahwa jarak minimal dari marker agar dapat terdeteksi dan menampilkan objek 3D adalah 10 $\mathrm{cm}$ dengan sudut maksimal $50^{\circ}$ dan jarak maksimal dari marker adalah $50 \mathrm{~cm}$ dengan sudut maksimal $50^{\circ}$. Pada jarak $60 \mathrm{~cm}$, kamera tidak bisa menampilkan objek 3D karena kamera tidak bisa mendeteksi marker.

3. Marker Terhalang Objek Lain

Pengujian marker terhalang objek lain terhadap marker pertama, kedua, dan ketiga dilakukan sebanyak 5 kali dengan menggunakan smartphone yang sama dan waktu yang sama yang dapat dilihat pada tabel 3 .

Tabel 3. Pengujian Marker Terhalang Objek Lain

\begin{tabular}{|c|c|}
\hline Kasus yang diuji & Hasil Uji \\
\hline Marker pertama terhalang objek lain & Tidak muncul objek 3D \\
\hline Marker kedua terhalang objek lain & Tidak muncul objek 3D \\
\hline Marker ketiga terhalang objek lain & Tidak muncul objek 3D \\
\hline
\end{tabular}


Berdasarkan pengujian pada tabel 3, dapat diambil kesimpulan bahwa kamera tidak bisa menampilkan objek 3D apabila marker yang digunakan terhalang oleh objek lain. Hal ini terjadi karena kamera tidak bisa mendeteksi keseluruhan marker.

4. Marker Lain

Pengujian marker lain dilakukan sebanyak 5 kali dengan menggunakan smartphone yang sama dan waktu yang sama yang dapat dilihat pada tabel 4 .

Tabel 4. Pengujian Marker Lain

\begin{tabular}{|c|c|}
\hline Kasus yang diuji & Hasil Uji \\
\hline Marker lain & Tidak muncul objek 3D \\
\hline
\end{tabular}

Berdasarkan pengujian pada table 4, dapat diambil kesimpulan bahwa kamera tidak bisa menampilkan objek 3D apabila marker yang digunakan tidak diregistrasi. Hal ini terjadi karena kamera tidak bisa mendeteksi penanda yang ada pada marker tersebut.

\subsection{Hasil Pengujian Terhadap Marker}

Hasil pengujian pencahayaan, jarak, sudut, marker terhalang objek lain, dan marker lain dapat dilihat sebagai berikut:

1. Pencahayaan

Hasil pengujian pencahayaan dapat dilihat pada gambar 3.6 dan gambar 3.7.

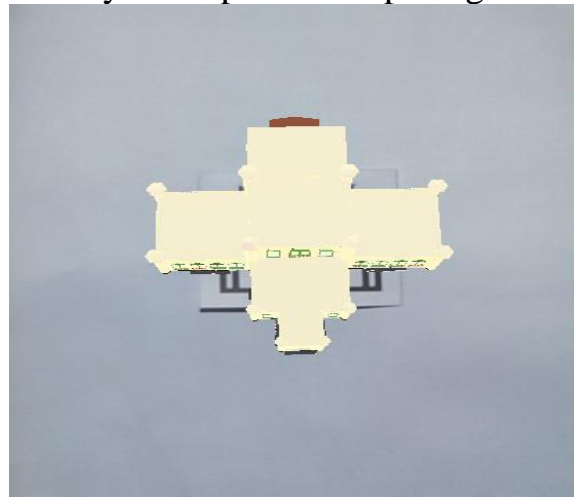

Gambar 3.6 Muncul Objek 3D Saat Ada Pencahayaan

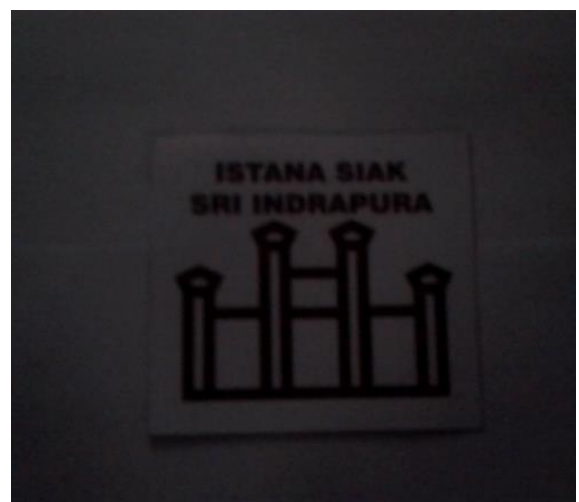

Gambar 3.7 Tidak Muncul Objek 3D Saat Tidak Ada Pencahayaan

2. Jarak dan Sudut

Hasil pengujian jarak dan sudut dapat dilihat pada gambar dibawah ini : 


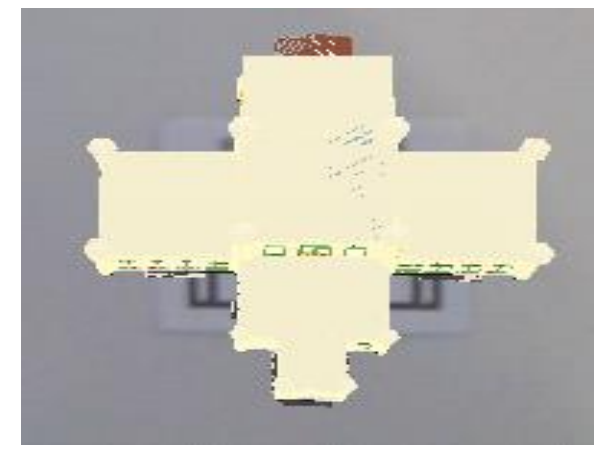

Gambar 3.8 Hasil Pengujian Jarak 50 cm dari Marker

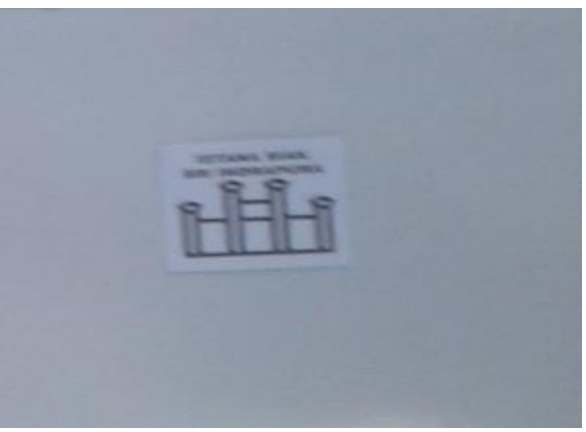

Gambar 3.9 Hasil Pengujian Jarak $60 \mathrm{~cm}$ dari Marker

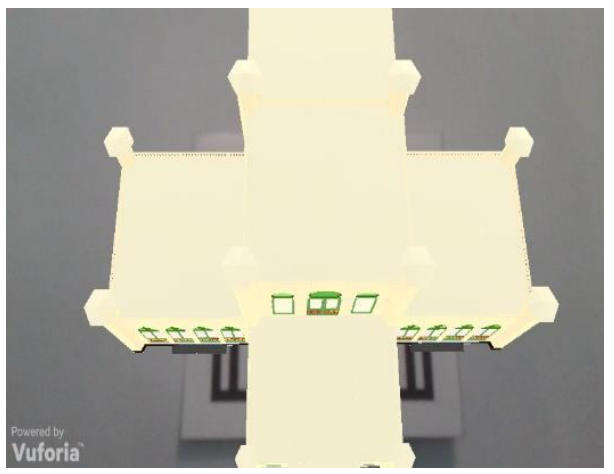

Gambar 3.10 Hasil Pengujian Sudut $1^{\circ}$ dari Marker

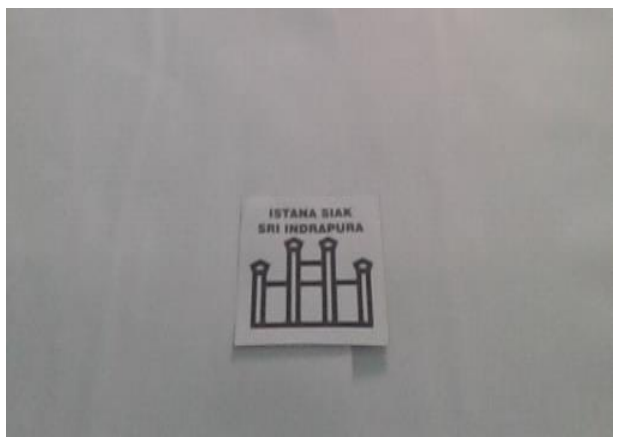

Gambar 3.11 Hasil Pengujian Sudut $6^{\circ}$ dari Marker

3. Marker Terhalang Objek Lain

Hasil pengujian marker terhalang objek lain dapat dilihat pada gambar 3.12. 


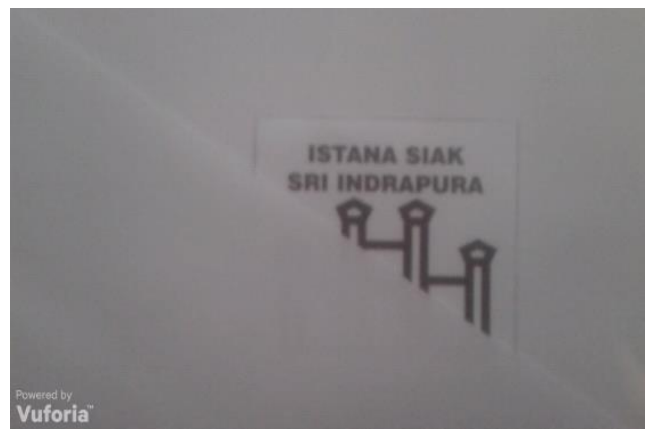

Gambar 3.12 Hasil Pengujian Marker Terhalang Objek Lain

4. Marker Lain

Hasil pengujian marker lain dapat dilihat pada gambar 3.13.

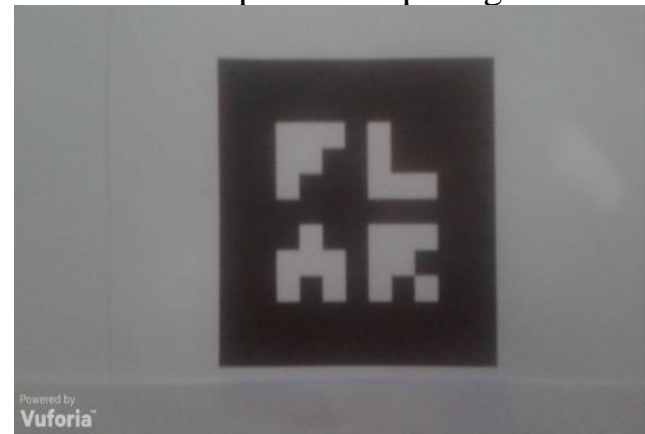

Gambar 3.13 Hasil Pengujian Marker Lain

\section{KESIMPULAN}

1. Augmented Reality merupakan teknologi yang dapat menggabungkan dunia nyata dan dunia virtual sehingga kita dapat berinteraksi secara langsung dengan objek virtual yang dibuat.

2. Aplikasi Augmented Reality Istana Siak Berbasis Android ini dapat mempermudah masyarakat berinteraksi dengan objek 3D Istana Siak Sri Indrapura secara realtime sehingga menarik minat masyarakat terhadap bangunan bersejarah serta dapat mempermudah masyarakat untuk mendapatkan informasi tentang Istana Siak.

3. Proses pendeteksian marker dipengaruhi oleh pencahayaan, jarak, sudut, marker terhalang objek lain, dan marker lain.

\section{SARAN}

1. Aplikasi Augmented Reality ini dapat dikembangkan dengan menambahkan fitur zoom, video, dan suara.

2. Untuk hasil yang lebih maksimal, aplikasi ini juga bisa dikembangkan dengan menghaluskan objek 3D Istana Siak agar terlihat lebih asli serta dapat menambahkan bangunan-bangunan bersejarah lain yang ada di Riau.

3. Aplikasi ini tidak hanya bisa berjalan di smartphone berbasis android, tetapi juga bisa dikembangkan di smartphone berbasis iOS.

4. Aplikasi Augmented Reality ini dapat dikembangkan dengan menggunakan media brosur dengan marker yang berwarna. 


\section{DAFTAR PUSTAKA}

[1] Roedavan, Rickman., 2014, Unity Tutorial Game Engine, Informatika, Bandung.

[2] Enterprise, Jubilee., 2015, Mengenal Dasar-Dasar Pemrograman Android, PT Ele Media Komputindo, Jakarta.

[3] Bintarto,Sandyarjo., 2013, Perancangan Aplikasi Pengenalan Beberapa Bagian Candi Borobudur Berbasis Augmented Reality, Skripsi, Universitas Muhammadiyah Surakarta.

[4] Chandra,Handi., 2013, 7 Jam Belajar Interaktif SketchUp 2013 Untuk Orang Awam, Maxikom, Palembang.

[5] Roedavan, Rickman., 2014, Unity Tutorial Game Engine, Informatika, Bandung.

[6] Bintarto Sandyarjo., 2013, "Perancangan Aplikasi Pengenalan Beberapa Bagian Candi Borobudur Berbasis Augmented Reality, Skripsi, Universitas Muhammadiyah Surakarta.

[7] Setiawan, Abas., Haryanto, Hanny., Wijayanti, Sari., 2012, Aplikasi Augmented Reality,Sebagai Promosi Bangunan Bersejarah di Kota Semarang. 